\title{
RECENT ADVANCES IN THE STUDY OF VENEREAL DISEASES*
}

\author{
BY \\ JOSEPH EARLE MOORE

\begin{abstract}
From the Johns Hopkins University and United States Public Health Service Venereal Disease Research and Postgraduate Training Centre, Baltimore, Maryland
\end{abstract}

This communication is a report of recent American advances in venereal disease research. It is my privilege to present these on behalf of a large group of American investigators, on the basis of the developments of the past two years.

\section{Gonorrhøea}

No evidence of penicillin resistance has as yet appeared. Procaine penicillin (of which more later) is curative in at least 95 per cent. of cases in a single intramuscular injection of 100,000 units. It is now clear that any method 'of treatment, including oral administration, which provides a measurable blood level of 0.03 units per ml. or more for a minimum of four hours is curative. Cure is so rapid and so nearly certain that in most large American clinics follow-up surveys and cultures have been abandoned.

In two U.S. Navy studies (Eagle, 1948 ; Campbell and others, in the press), penicillin, orally administered, has been shown to be of value in the prophylaxis of gonorrhœa. The circumstances of the studies, which differed slightly, are shown in Table I. When penicillin was administered orally within an estimated two hours after potentially infectious exposure, in a single dose of 0.25 mega units, the incidence of gonorrhœa in the treated group was reduced twelve-fold from that in a control untreated group. When the time interval of prophylactic treatment after definite exposure was increased to an average of fifteen hours, a single slightly smaller dose reduced incidence by one half. No evidence of suppression of simultaneously acquired syphilis has as yet been noted; nor has sensitization to penicillin become a problem.

In my own clinic and elsewhere a new antibiotic, aureomycin (of which more presently), is effective

- An Address delivered to a combined meeting of the Royal Society of Medicine, the Section of Experimental Medicine, and The Medical Society for the Study of Venereal Diseases, May 31, 1949. The investigations recorded were supported by various grants-in-aid from investigations recorded were supported by various grants-in-aid from the Research Grants and Fellowships Divisiog,
Health, and United States Public Health Service. against gonorrhœa when administered orally in two or three divided doses of 250 to $500 \mathrm{mg}$. . As long as penicillin remains so effective and so inexpensive, however, the routine use of aureomycin does not seem likely to be adopted. As with penicillin, it should not be administered to patients

TABLE I

THE PROPHYLAXIS OF GONORRHCEA BY THE ORAL ADMINISTRATION OF PENICILLIN (U.S. NAVY)*

\begin{tabular}{|c|c|c|c|c|}
\hline & \multirow{2}{*}{$\begin{array}{l}\text { Dose } \\
\text { of oral } \\
\text { peni- } \\
\text { cillin } \\
\text { (mega- } \\
\text { units) }\end{array}$} & \multirow{2}{*}{$\begin{array}{l}\text { Esti- } \\
\text { mated } \\
\text { elapsed } \\
\text { time } \\
\text { after } \\
\text { expo- } \\
\text { sure }\end{array}$} & \multicolumn{2}{|c|}{$\begin{array}{l}\text { Incidence of } \\
\text { gonorrhoea per } \\
1,000 \text { leaves }\end{array}$} \\
\hline & & & $\begin{array}{l}\text { Con- } \\
\text { trols } \\
\text { (no } \\
\text { peni- } \\
\text { cillin) }\end{array}$ & $\begin{array}{l}\text { Peni- } \\
\text { cillin }\end{array}$ \\
\hline $\begin{array}{l}\text { After all shore } \\
\text { leaves (no other } \\
\text { prophylaxis) }\end{array}$ & 0.25 & 2 hours & 11.9 & 0.9 \\
\hline \multirow{2}{*}{$\begin{array}{l}\text { After admitted } \\
\text { exposure on } \\
\text { leave (station } \\
\text { prophylaxis } \\
\text { also used) }\end{array}$} & \multirow[b]{2}{*}{$0 \cdot 2$} & \multirow[b]{2}{*}{15 hours } & \multicolumn{2}{|c|}{$\begin{array}{l}\text { Incidence of } \\
\text { gonorrhœa per } \\
1,000 \text { exposures }\end{array}$} \\
\hline & & & $11 \cdot 6$ & $4 \cdot 7$ \\
\hline
\end{tabular}

- Modified from Eagle (1948) and from Campbell and others (in the press).

with gonorrhœa who also present lesions suspicious of but not yet diagnosed as syphilis, since aureomycin also possesses treponemicidal activity, as will be later shown.

Streptomycin is also curative in 90 to 95 per cent. of the patients with gonorrhœa in a single intramuscular injection of 0.5 to $1.0 \mathrm{~g}$. Since this drug has no treponemicidal effect, and since 
reactions are not to be feared in this small dosage, streptomycin is the preparation of choice when gonorrhoa is complicated by possible but not yet diagnosed syphilis.

\section{Syphilis}

Multiplication of Virulent $T$. pallidum in vivo.Magnuson and others (1948), and Cumberland and Turner (1949), working independently and with different but in each case a quantitative technical approach, have calculated that the multiplication time of $T$. pallidum in the rabbit is thirty to thirtythree hours per single division. This experimental demonstration is of great practical importance, as will appear, in the clinical application of penicillin therapy.

Cultivation of $T$. pallidum on Artificial Media.The very corner stone of further knowledge of the biology of syphilitic infection, of immunity, of the development of a specific diagnostic test, and of a possible test for cure, depends on the successful cultivation of virulent $T$. pallidum on artificial media. In the past, success has been reported by several investigators, but in each case the results have not been consistent in the hands of the original reporter, and could not be confirmed by others. One or both of two alternatives are suggested by this past work: (a) that success depended on some small unidentified "trick" of technique, the lack of clear definition preventing repetition; or (b) that virulent organisms, adapted to test-tube life, rapidly lost virulence.

At least six groups of American investigators have, however, approached the problem afresh, in the light of new bacteriologic knowledge. Newcomer and Hannes (personal communication), of the University of Pennsylvania, have shown that the Nichols strain of cultured non-virulent spirochætes can be made to multiply rapidly in anærobically incubated fertile hen's eggs which have been killed by asphyxiation immediately after inoculation. This is in contrast to almost complete lack of success in the living chick embryo. Organisms so cultivated revert in morphology to the typical appearance of virulent $T$. pallidum; and early experience suggests the possibility that passage from the test tube through the killed fertile egg may restore virulence. Experiments with virulent organisms, derived from rabbit or man, are just beginning.

Boak and Carpenter (1949b), working with virulent $T$. pallidum derived from rabbit testicular syphilomas, and on an artificial culture medium based on a modified Brewer's thioglycollate formula fortified with goose serum, have observed survival of organisms in the originally inoculated tube for as long as ninety-seven days; have successfully transferred subcultures through at least five generations ; and are reasonably certain of actual multiplication. The organisms so cultured have the typical morphology of $T$. pallidum, but, as yet, rabbits inoculated with cultured spirochætes have failed to develop syphilis after a maximum incubation period of fifty-six days.

Also using a basic artificial medium, Nelson (1948), from my own university, has shown that actively motile and still virulent $T$. pallidum can be induced to survive for ten to fourteen days. Actual cultivation has not yet been accomplished; but the work has formed the basis for the first demonstration of a treponemicidal antibody in vivo, presently to be discussed.

While these results do not yet represent complete conquest of the basic problem, progress has been made and there is hope for final solution.

Immobilization of $T$. pallidum in vitro by Antibody Produced in Syphilitic Infection.-The most significant immunological advance since the original work of Wassermann, Neisser, and Bruck has been accomplished by Nelson and Mayer (1949) within the past few months. These workers have shown that in the serum of syphilitic rabbits or man, but not of normal rabbits or man nor of a limited number of persons suffering from infections or diseases other than syphilis, there is present an antibody which immobilizes and probably kills virulent $T$. pallidum. The organisms are extracted from rabbit testicular syphilomas and suspended, in comparatively tissue-free extract, in the special basic medium referred to above. Under these conditions the organisms remain motile and infectious for several days. On incubation of such suspensions with syphilitic rabbit or human sera plus guinea-pig complement, the treponemes become non-motile and lose their capacity to infect rabbits. This antibody is distinct from reagin. It is also present in spinal fluid from syphilitic patients.

The test is as yet on a wholly experimental basis and its kinetics are still under investigation. It is unlikely to be a feasible technical procedure until successful cultivation of the virulent treponeme has actually been accomplished. Nevertheless, as the authors point out, it "offers a convenient approach to the study of certain fundamental problems in the biology of the disease in animals. and man. These include a study of: (a) the incidence and titre of immobilizing antibody in various stages of syphilitic infection in human beings ; (b) the rate of appearance of immobilizing antibody during experimentally induced syphilis in rabbits, and its quantitative relationship to the 
development of immunity, as measured by resistance to reinfection ; $(c)$ the possible absence of immobilizing antibody in non-syphilitic individuals whose sera contain reagin, that is, the biologic false positive reactors; $(d)$ the immunological relationships among experimentally induced yaws, rabbit venereal spirochætosis, and syphilitic infections in rabbits; and $(e)$ the possible immunological variations among different strains of $T$. pallidum."

All these and other related problems are under active study by Nelson and his associates in Turner's laboratory at the Johns Hopkins School of Hygiene and Public Health, with the active collaboration of my clinical staff. Already it has been shown (Nelson and others, 1949) that the method holds great promise in differentiation of biological false positive tests from those actually due to syphilis.

Immunity in Syphilis.-Magnuson and others (1948) at North Carolina have provided quantitative information of value as to the rate of development, degree, and duration of acquired immunity in experimental syphilis. Assuming the state of affairs in man to be identical with that in the rabbit, Magnuson suggests that increasing immunity may

TABLE II

THE PROBABILITY OF REINFECTION, SYMPTOMATIC OR ASYMPTOMATIC, OR OF PERSISTENT IMMUNITY IN SYPHILITIC MAN ORIGINALLY TREATED FOR AND " CURED " OF EARLY SYPHIII"

\begin{tabular}{|c|c|c|c|}
\hline \multirow{2}{*}{$\begin{array}{l}\text { Patients } \\
\text { originally } \\
\text { treated in }\end{array}$} & \multicolumn{3}{|c|}{$\begin{array}{l}\text { May be expected, if exposed } \\
\text { to reinfection, to develop } \\
\text { (approximate per cent.) }\end{array}$} \\
\hline & $\begin{array}{l}\text { Symp- } \\
\text { tomatic } \\
\text { rein- } \\
\text { fection }\end{array}$ & $\begin{array}{l}\text { Asymp- } \\
\text { tomatic } \\
\text { rein- } \\
\text { fection }\end{array}$ & $\begin{array}{l}\text { No rein- } \\
\text { fection } \\
\text { (persistent } \\
\text { immunity) }\end{array}$ \\
\hline $\begin{array}{ll}\text { Primary stage } & \ldots \\
\text { Secondary stage } & \ldots \\
\text { Early latent } & \ldots\end{array}$ & $\begin{array}{r}50 \\
7 \\
0\end{array}$ & $\begin{array}{l}26 \\
43 \\
13\end{array}$ & $\begin{array}{l}24 \\
50 \\
87\end{array}$ \\
\hline
\end{tabular}

- After Magnuson and Rosenau (1948).

have a direct relationship to apparent cure rates in various stages of human syphilis. Assuming further that recent infections in man are as readily curable as in the rabbit with, for example, penicillin, exposure to reinoculation may result in symptomatic or asymptomatic reinfection (the latter manifest if at all only by apparent serologic relapse), or by lasting immunity to reinoculation, in the proportions shown in Table II. While this transference from animal to man represents speculative hypothesis only, it conforms nevertheless to observed clinical fact.
Strains of $T$. pallidum.-That there may be as much difference between strains of $T$. pallidum as of other bacteria is suggested by two studies. Boak and Carpenter (1949a) found that the curative dose of penicillin $G$ in experimental rabbit syphilis, measured in $\mathrm{u} / \mathrm{kg}$, varied several-fold with different strains of organisms. Turner and Cumberland (1949) cross-challenged infected rabbits with about ten different strains of $T$. pallidum, and found at least three totally unlike infective strains. The importance of these early studies lies in the fact that one of the factors contributing to treatment failure in early syphilis in man may be strain susceptibility to treponemicidal drugs.

Serology of Syphilis.-Though Nelson's work on treponemicidal antibody is of the highest importance to the eventual development of a wholly new, more sensitive, and perhaps absolutely specific serologic test for syphilis, it is certain that at least for the next decade reliance must still be placed on the present non-specific lipoid antigens for the detection of the equally non-specific reagin. For this reason the attention of American serologists is largely centred on the use of cardiolipin antigen. First discovered by Pangborn, cardiolipin is a highly purified phospholipid antigenically active in the presence of lecithin and cholesterol. It gives great promise of the development of a test which is both more sensitive and more specific than standard beef heart extracts. Theoretically, it should lead to the development of a standardized, reproducible technique which can replace present tests. The theoretical hope has not yet been realized. American serologists, who will perhaps forgive me if I describe them as individualistic prima donnas, have in general tried to adapt cardiolipin to their already existing techniques; are unable to agree among themselves as to whether it is best employed with complement fixation or micro- or macro-flocculation techniques; are equally unable to agree on the optimum concentration of the three necessary ingredients; and tend to adjust sensitivity and specificity on the basis of individual whims, rather than at the level desired by the clinician. Nevertheless, in the hands of most workers, cardiolipin represents a great advance, too little known in Europe.

The physicochemical and immunologic differences between syphilitic sera and those which are biologically false sero-positive continues in the laboratories of Neurath and his collaborators at Duke University. Qualitative differences in the "reagin" produced under the two sets of circumstances has been demonstrated ; and the " euglobuin-inhibitor" test, while still on an experimental 
basis, is the only one of the so-called "verification tests" which offers any promise of eventual practical usefulness.

\section{The Penicillin Therapy of Syphilis}

In writing of the use of penicillin in the treatment of syphilis I have deliberately avoided detailed documentation, though a few references seemed essential.

Procaine Penicillin.-The most important recent development is the introduction and rapid general adoption of procaine penicillin $\mathrm{G}$ as a method of delaying penicillin absorption. This drug, which contains approximately $40 \mathrm{mg}$. of procaine for each $60 \mathrm{mg}$. of penicillin, is highly insoluble in

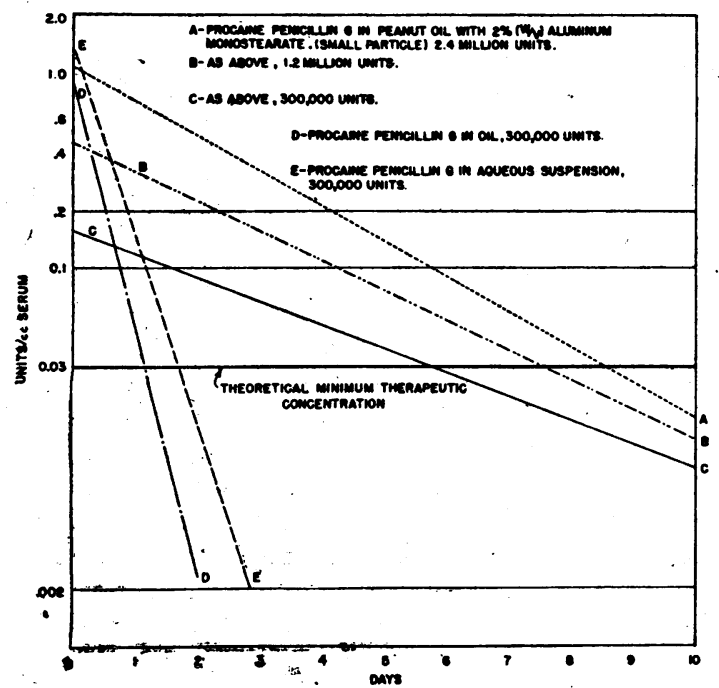

FIG. 1.-Average penicillin blood concentrations produced with single injections of three repository penicillin preparations (from Thomas and others, in the press).

water or tissue fluids. Both in vitro and in vivo it possesses the bactericidal spectrum of penicillin $\mathbf{G}$ itself, and is practically non-toxic. It may be administered either in aqueous suspension, or in a suspension of peanut or sesame oil to which has been added 2 per cent. of the water-repellent aluminum monostearate. The oil suspensions provide measurable serum levels of penicillin for a longer average time than aqueous suspensions. In oil a single dose of 0.6 mega units provides a serum level of or above $0.03 \mathrm{u} / \mathrm{ml}$. for five to seven days, though peak levels are far below those attainable with aqueous solutions of penicillin G (Thomas and others, in the press :. Fig. 1). Since in early syphilis, at least, results appear to depend on prolonged maintenance of a low blood and tissue level, rather than on repeated high peaks, procaine penicillin $G$ has practically replaced penicillin $G$, and the treatment of syphilis has become an ambulatory rather than a hospital procedure. The relative merit of procaine penicillin and of penicillin $G$ in aqueous solution in infections other than syphilis is -beyond the scope of this discussion.

Procaine penicillin provides a lower incidence of toxic allergic reactions than penicillin in oil-beeswax or even of aqueous solutions of penicillin $\mathrm{G}$, perhaps because procaine is thought to have some antihistaminic effect.

Early Syphilis.-Data as to the efficacy of procaine penicillin in early syphilis in man are not yet available. By analogy with the results of penicillinoil-beeswax, however, the treatment system now in vogue is usually 6 mega units of procaine penicillin $\mathrm{G}$, given in ten intramuscular injections, daily to every third day. It is anticipated that the failure rate from this regimen will approximate the usual ten to fifteen per cent. of failure (at eighteen to twenty-four months) observed after aqueous penicillin $\mathbf{G}$ or penicillin-oil-beeswax.

On a purely experimental basis, several clinics are now studying the effect of greatly shortened treatment. Since 0.6 to 1.2 mega units of procaine penicillin $\mathrm{G}$ provides a measurable blood level for about one week, series of cases are under study utilizing four schedules: (a) a single injection of 0.3 mega units; (b) a single injection of 1.2 mega units ; (c) 1.2 mega units, two injections, 7 days apart ; (d) 1.2 mega units, three injections, each 7 days apart. Preliminary results with these are encouraging; and, in early syphilis at least, it seems possible that a single dose therapy may actually be in sight. It is as yet too early, however, to provide definite results, or to abandon the largerdose-longer-duration regime.

Prophylactic (Early Abortive) Treatment of Syphilis.-Adapting the experimental data, that the curative dose of penicillin is related both to the duration of infection and the number of organisms in the infecting inoculum, two groups of American workers (Alexander and others, in the press; Plotke and others, in the press) have explored the practicability of early abortive treatment in man. Patients exposed by sexual contact to persons with proved infectious early syphilis have been divided into control and treated groups. In 215 control cases the incidence of fresh infections among contacts is about 60 per cent. To 297 exposed persons a single injection of 0.6 to 0.9 mega units of procaine penicillin was given as soon as the infectiousness of the exposure was established, 
FIG. 2.-Typical curves of serological response during the first post-treatment year in penicillin-treated early syphilis (from Hoekenga and others (1949)). The vertical line represents the STS titre. This is arbitrarily shown in range 0 to 100 to distinguish between highand low-titre tests. The horizontal line indicates the time after treatment, the length of the line representing one year. The curves are schematic.
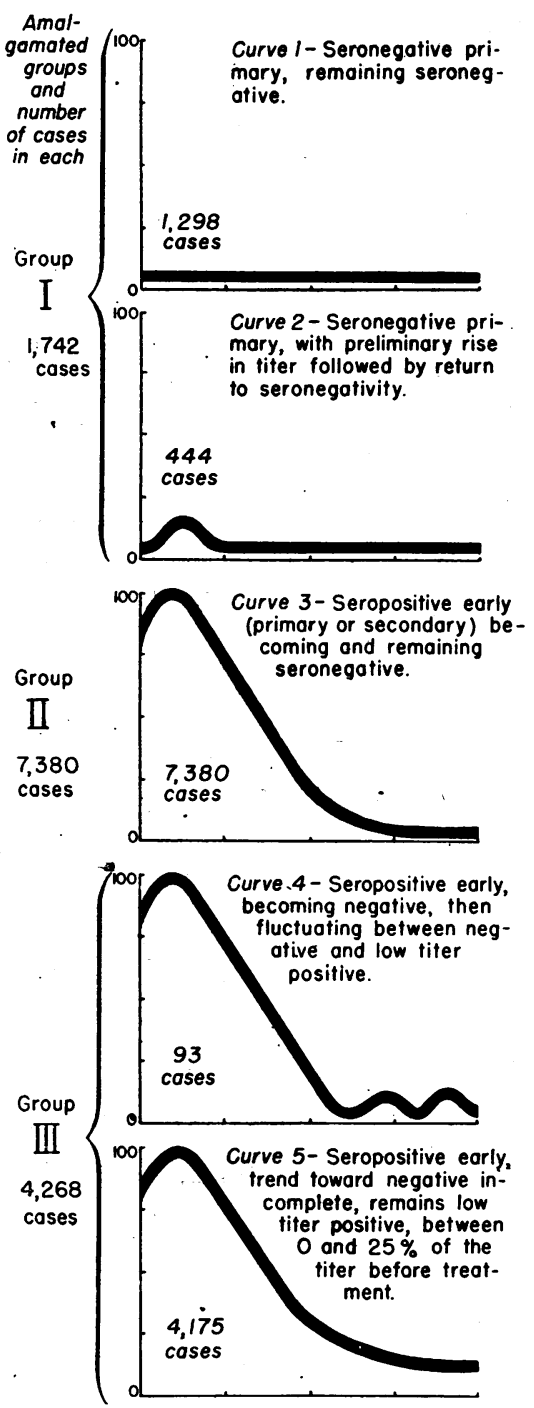
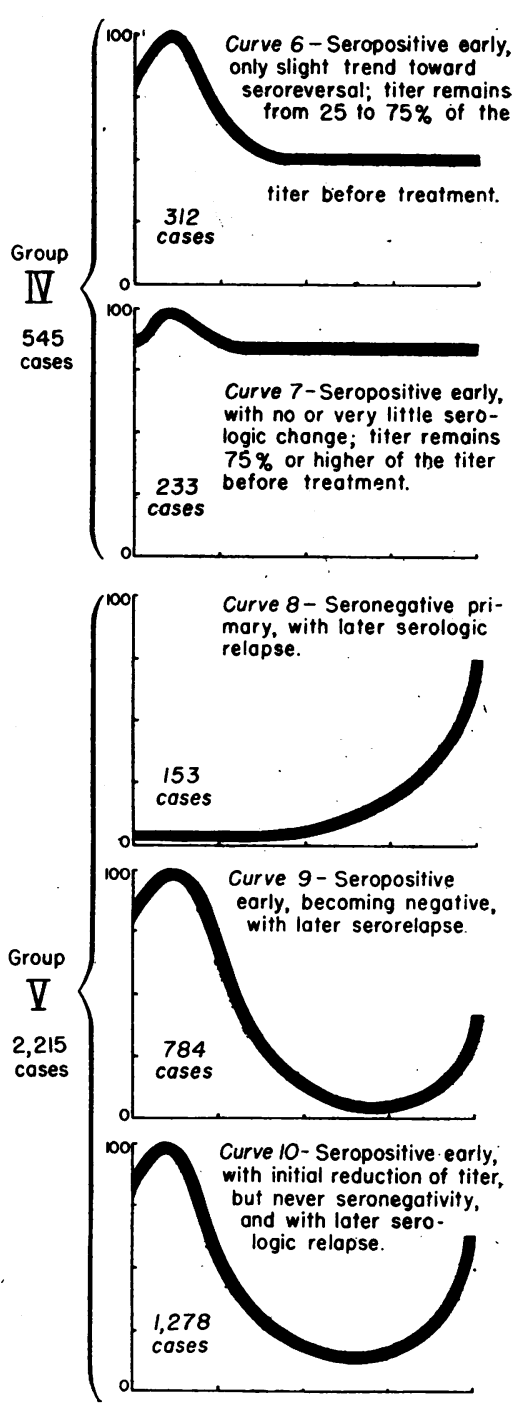

that is, at intervals of a few hours to several weeks after exposure, but at a time when none of the contacts showed any evidence of infection. In such " protected" persons, the incidence of later primary and secondary syphilis was reduced tenfold (Table III) ; and most of the observed infections are thought actually to be reinfections, on the basis of subsequent unprotected contact. The procedure of early abortive treatment is now well established, and offers further evidence of the remarkable efficacy of a single small dose of penicillin in curing very early infections.

Failure Rates in Early Syphilis and their Relation to Serological Pattern.-From my own clinic,
Hoekenga and others (1949) have examined the relationship of clinical failure to serologic response within the first post-treatment year in nearly 16,000 persons with early syphilis. There are at least ten characteristic types of serologic response to treatment, shown in Fig. 2. When patients exhibiting these types of serologic response are examined as to the incidence of early clinical failure, this incidence is low : (a) when the blood serological test for syphilis (STS) remains, or becomes and remains, sero-negative ( 7 to 9 per cent. at three years); (b) when the STS remains weakly positive, in low quantitative titre (12 per cent. at three years). On the other hand clinical relapse is frequent: (c) when the STS persists for six months 


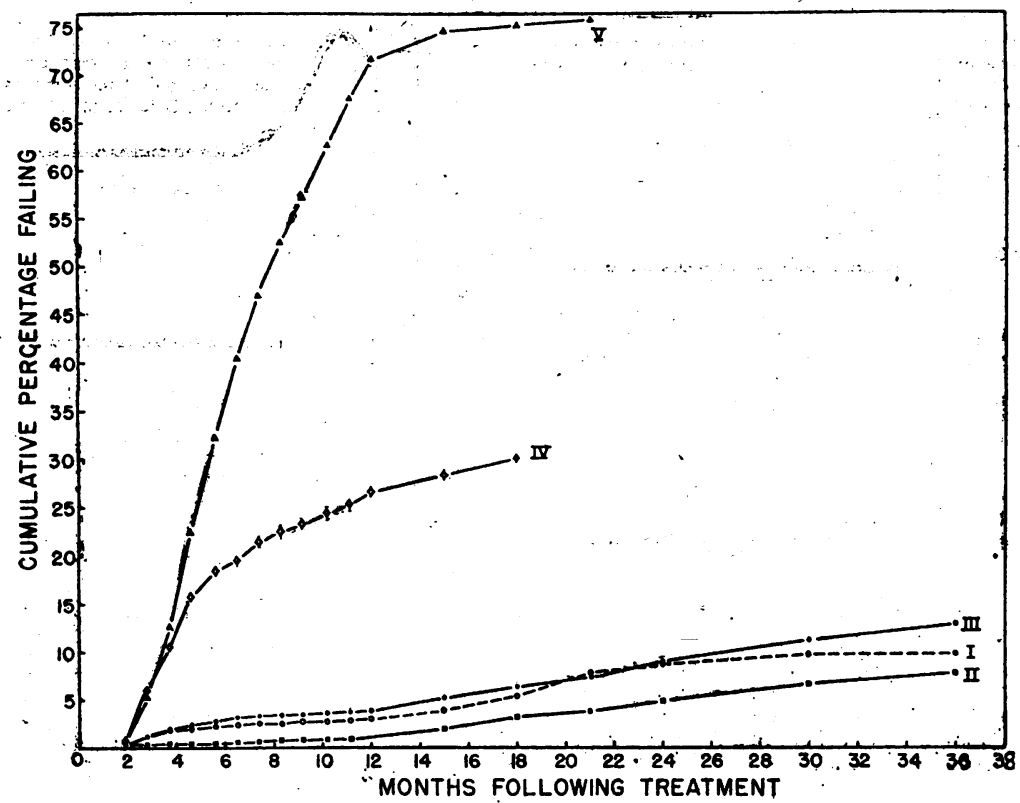

FIG. 3.-Cumulative clinical failure rates by serological type in penicillin-treated early syphilis (from Hoekenga and others (1949)).

or longer in high titre (30 per cent. at eighteen months); $(d)$ when sero-relapse occurs (75 per cent. at eighteen months).

These data are illustrated by Fig. 3, and are of practical importance in estimating the necessity for careful quantitative serologic follow-up of all treated patients; in estimating the necessity for retreatment on serologic grounds in order to anticipate clinical relapse; and probably in differentiating relapse from reinfection.

TABLE III .

THE PROBABILITY OF ACQUIRING $\Sigma$ AFTER EXPOSURE TO A KNOWN INFECTIOUS SEXUAL CONTACT*

\begin{tabular}{l|c|c|c}
\hline $\begin{array}{c}\text { Non-syphilitic } \\
\text { exposed persons }\end{array}$ & Cases & $\begin{array}{c}\text { Number } \\
\text { develop- } \\
\text { ing early } \\
\Sigma\end{array}$ & $\begin{array}{c}\% \\
\text { infected }\end{array}$ \\
\hline Untreated controls . & 215 & 115 & $53 \cdot 4$ \\
\hline $\begin{array}{c}\text { Abortive R (600,000- } \\
900,000 \text { units pro- } \\
\text { caine penicillin) } \\
\text { within average 6 } \\
\text { d a y s a f t e r }\end{array}$ & 297 & 16 & $5 \cdot 4$ \\
exposure
\end{tabular}

* From Alexander and others and Plotke and others (both in the press).

Prenatal Syphilis.-Further experience has confirmed the fact that penicillin administered to the pregnant syphilitic woman provides almost certain protection against infection of the fœtus or, alternatively, the actual cure of established intrauterine

fotal syphilis The infantile failure rate in several thousands of patients is now only 1 to 2 per cent. These results are accomplished, regardless of the duration of infection in the mother and even under

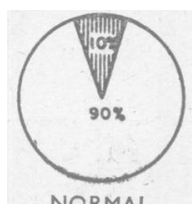

NORMAL

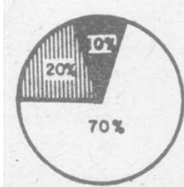

LATE SYPHILIS ( $>4$ YEARS)
UNTREATED

$Q=$ NORMAL LIVING INFANT

$\nabla=$ ACCIDENTS OF PREGNANCY (prematurity, miscarriage, stillbirth, neonatal death) $=$ SYPHILITIC LIVING INFANT

FIG. 4.-Outcome of pregnancy in normal and syphilitic women (without and with treatment according to the duration of maternal $\Sigma$ ).

the circumstances, most dangerous for the fœtus, of recent maternal infection. The incidence of normal living children, of accidents of pregnancy, including miscarriage, stillbirth and neonatal death, 
and of living syphilitic infants under varying sets of circumstances are shown in Fig. 4. In normal non-syphilitic women about 10 per cent. of pregnancies end with one or another accident. In mothers infected with syphilis shortly before or during pregnancy, and given no treatment, the incidence of normal children is practically nil. About half the pregnancies end in miscarriage or still-birth; the other half result in living syphilitic infants. With increasing duration of syphilitic infection in the mother, and even in the absence of treatment, the incidence of normal children increases, but a substantial number of pregnancies still end in disaster. In the pre-penicillin era, when reliance was placed entirely on metal chemotherapy, only about 65 per cent. of infants delivered of mothers with treated early syphilis were themselves normal. Now, when mothers with early syphilis are treated with penicillin, the accidents of pregnancy are no more frequent than in normal women, and there are scarcely any syphilitic children born.

As I have previously pointed out, there is involved here a double paradox : penicillin appears to be more effective in the treatment of established intrauterine syphilis in the fotus than in the mother herself; and this is in spite of the facts that fotal infection, in contrast to the acquired disease in adults, is thought to be overwhelmingly severe; and that the concentration of penicillin in fotal blood and tissues is substantially less than in the maternal tissues.

In any case, the treatment of syphilis in pregnant women by any other means than penicillin seems no longer to be justified.

Necessity for Retreatment of Syphilitic Pregnant Women in Every Pregnancy.-The accepted point of view in practically all countries has been that every syphilitic woman should be treated during every pregnancy, regardless of her own status, for the sake of protection of the fœtus. This point has been subjected to detailed study in my own clinic, with regard to both metal chemotherapy and penicillin administered to the mother. We have now shown that the original concept was erroneous. Goodwin and Farber (1948) have studied 363 women with varying types of syphilitic infection who previously received metal chemotherapy, and who were observed through 570 subsequent pregnancies in which further antisyphilitic treatment was purposely omitted. Not one of the infants born during these subsequent untreated pregnancies had syphilis.

Tucker (1949), likewise from my clinic, has conducted a similar study of eighty-eight women with penicillin-treated early syphilis, permitted to go through one or more subsequent pregnancies without additional antisyphilitic treatment. Tucker's results have been further amplified by Thomas (1948) and by Ingraham (1948). From these three sources, records are now available of 390 pregnancies among women with early syphilis treated with penicillin, treatment being deliberately withheld during one or more later pregnancies, with only three syphilitic infants among the total.

TABLE IV

NECESSITY FOR RETREATMENT OF SYPHILITIC PREGNANT WOMEN IN EVERY PREGNANCY

\begin{tabular}{c|c|c|c}
\hline $\begin{array}{c}\text { Previous } \\
\text { treatment }\end{array}$ & $\begin{array}{c}\text { Number of } \\
\text { subsequent } \\
\text { pregnancies } \\
\text { in which } \\
\text { treatment was } \\
\text { withheld }\end{array}$ & $\begin{array}{c}\text { Number of } \\
\text { syphilitic } \\
\text { infants }\end{array}$ & $\begin{array}{c}\text { Per cent. of } \\
\text { syphilitic } \\
\text { infants }\end{array}$ \\
\hline $\begin{array}{c}\text { Metal } \\
\text { chemo- } \\
\text { therapy .. }\end{array}$ & $570^{1}$ & 0 & 0 \\
\hline Penicillin .. & $390^{2}$ & 3 & 0.77 \\
\hline
\end{tabular}

1. Goodwin and Farber (1948).

2. Thomas (1948); Ingraham (1948); Tucker (1949).

These data permit, we think, important conclusions. It is not necessary to administer antisyphilitic treatment to a syphilitic woman during every pregnancy. There is a high degree of probability that the infant will be normal if maternal treatment is withheld, regardless of the stage and duration of syphilitic infection in the mother, and regardless of the interval between previous treatment and the untreated pregnancy in question; provided that the mother has received $4 \mathrm{~g}$. or more of arsphenamine or its arsenical equivalent, together with concomitant bismuth, or 2.4 or more mega units of penicillin. We have qualified this, however, pending further evidence, by insisting that during a pregnancy proposed to be untreated the mother herself shall show no clinical signs of active syphilitic infection, and that she shall be sero-negative or, if sero-positive, in low titre only.

Cardiovascular Syphilis.-Evidence has now accumulated, on the basis of several thousand patients treated in my clinic and elsewhere, that penicillin in cardiovascular syphilis almost certainly does no harm, and that the Jarisch-Herxheimer reaction is not to be feared. The few reports of apparent Herxheimer reactions may well be no more than coincidence. On the other hand there is as yet no evidence that penicillin in cardiovascular syphilis is of appreciable benefit in terms of prolongation 
of life. The proof of this point must wait several years of further study and of detailed biostatistical comparison of the results in penicillin-treated patients as compared with the outcome in identical groups of patients given no specific treatment at all, or treated with metals. Pending the acquisition of this detailed information, it seems nevertheless desirable to utilize penicillin in the treatment of persons with aortic insufficiency and saccular aneurysm in place of the prolonged metal chemotherapy heretofore employed.

Neurosyphilis.-It has been amply demonstrated that penicillin is even more effective in neurosyphilis than in early syphilis. As judged by the results of laboratory examinations of the spinal fluid, the cell count and protein content become normal in 90 to 95 per cent. of all patients, regardless of the clinical type of neurosyphilis, within six months after the institution of penicillin therapy. The complement fixation test and colloidal tests progress toward normal more slowly, but do so to the same degree and with approximately the same speed as after any other type of treatment, including fever therapy. The clinical results of treatment are likewise excellent to the extent to which inflammatory lesions predominate over actual degeneration in the brain or spinal cord. These results, once attained, appear to be permanent in at least 90 per cent. of patients treated.

Almost the only remaining point at issue is whether penicillin alone provides results as good as those obtainable with penicillin plus fever therapy. As evidence accumulates, there is no actual biostatistical proof of improved results from combined treatment, and American opinion gradually swings toward the point of view that penicillin alone, administered in a total dose of from 6 to 20 mega units over a period of ten to twenty-five days, accomplishes far more than was ever possible with metal chemotherapy, of no matter what type or duration, and as much as can be accomplished with fever. In addition, the use of penicillin alone obviates practically all risk of treatment. Those American workers who still cling to the desirability of combined fever and penicillin (and I am numbered among these) do so on the basis of clinical impression in individual cases ; and, moreover, tend to limit the use of such combined treatment to those types of neurosyphilis which carry a grave risk to life, sanity, or vital function. Included in this group are all cases of general paresis, primary optic atrophy, nerve deafness, Erb's spinal spastic paraplegia, and many cases of tabes dorsalis. All other types of neurosyphilis appear to do equally well on penicillin alone.
Still unexplained is the paradox of such favourable results, in spite of the fact that penicillin does not appear to penetrate the nervous system in the same concentration as in other tissues of the body. A partial explanation has been offered by Tucker from my department, who has demonstrated that in vitro the penicillin is, in some as yet unexplained manner, bound or destroyed by spinal fluid.

Jarisch-Herxheimer Reaction.-The Herxheimer reaction has been under intensive study in my clinic (Farmer, 1948 ; Hoekenga and Farmer, 1948) and elsewhere by a group of investigators who have developed a number of important points. Febrile reactions in early syphilis occur in about half the patients treated; and with equal frequency and severity, regardless of the stage or duration of the infection. The temporal pattern of the febrile reaction is uniform and does not depend on dose. The reaction is an all-or-none phenomenon which does not occur with minute doses $(10 \mathrm{u} / \mathrm{kg}$. or less), but does occur with equal frequency and severity with any dose larger than this. In early syphilis febrile reactions occur with single doses of penicillin so small as to have no obvious treponemicidal effect. In central-nervous-system syphilis there is a remarkable difference in the incidence of febrile Herxheimer reactions depending on the type of neurosyphilis. In patients with general paresis with active spinal fluids (cell count and protein content increased) the reaction occurs in 95 per cent. In other types of neurosyphilis only about 25 per cent. suffer such febrile reactions. Here too, as in early syphilis, the reaction is an all-or-none phenomenon which cannot be prevented by the initiation of treatment with small doses.

From the clinical point of view, Herxheimer reactions have not been troublesome except in patients with general paresis. Here, in our own experience, about 10 per cent. of paretics in.whom treatment was initiated with penicillin have developed, within the first forty-eight to seventy-two hours of treatment, important and sometimes very serious reactions consisting of focal vascular accidents, an exacerbation of psychosis, or a transformation of its type. The importance of such clinical reactions is such as to make me feel that in general paresis, if in no other type of neurosyphilis, treatment should be initiated with fever, penicillin being added to the treatment course only after fever from induced tertian malaria has become well established.

The fact that Herxheimer reactions cannot be avoided by the administration of small doses of penicillin is important in all phases of syphilitic infection, and particularly in cardiovascular syphilis, 
where it -seems unlikely that the reaction, if it occurs at all, can be minimized by preliminary caution.

These observations throw some doubt on the usually accepted explanation of the mechanism of the Herxheimer reaction, but do not as yet suggest a satisfactory alternative hypothesis.

\section{The Dynamics of Penicillin Action}

The following discussion is largely taken from Eagle's (1949) stimulating paper. Experimental and clinical data so far available indicate that the action of penicillin in syphilis does not differ qualitatively from that in other bacterial infections. Regardless of the infection for which the drug is used, its action is largely defined by the total time for which it remains in the tissues at concentrations lethal to the particular organism. Though wide variations in the absolute curative dose, on different schedules of penicillin administration, may be noted in syphilis as in other infections, these variant schedules have in common the fact that they provide effective levels for essentially the same total period of time.

The maximum effective blood and tissue level in penicillin of course varies according to bacterial species and for different strains of the same species. The Treponema pallidum is exquisitely sensitive to penicillin, and experimental syphilis in animals may be cured by the prolonged and repeated administration of doses so small that a level of penicillin detectable by the usual means never appears in the blood.

The point is arguable whether large concentrations of penicillin are more effective than low concentrations. For all organisms so far tested, the range between minimum bactericidal and maximally effective concentrations is narrow. However, large doses may have two advantages over small doses. First, the large dose may provide a sterilizing concentration in tissues not readily penetrated by small doses ; ' and, second, effective levels may be provided for a longer period of time, thereby reducing the number of injections.

Penicillin-susceptible infections differ markedly in the length of time for which penicillin must be kept at an effective concentration. Gonorrhœa may be cured by doses so small that effective levels are present for only two or three hours. Syphilitic infection, on the contrary, demands an effective tissue concentration in rabbits for at least thirty hours and in man for considerably longer, probably ninety-six hours or more. At least in part, the difference between these two infections lies in the relative multiplication times of the two organisms. That of $N$. gonorrhcee is perhaps a few minutes; that of $T$. pallidum in vitro is now accurately estimated at about thirty hours.

In syphilis as well as in other penicillin-susceptible infections, two further points are of importance. These are the duration of the infection and the number of organisms in the body. The earlier treatment is instituted, the smaller the effective dose and the shorter the time required for cure. To quote Eagle : "The amount of penicillin required to abort an infection soon after an exposure should be, and is, a minute fraction of the amount necessary to cure the established infection." The practical importance of this has already been mentioned with regard to the prophylactic treatment of gonorrhœa and the early abortive treatment of syphilis in man.

It has now been shown further that in syphilis, as well as in other infections, it is not necessary that effective concentrations of penicillin be continuously maintained. Pathogenic organisms briefly exposed to penicillin, whether in vitro or in vivo, do not immediately resume multiplication when the penicillin is removed. Instead there follows a variable period during which bacteria not only fail to multiply, but remain susceptible to the defence mechanisms of the host. Having regard to the multiplication time of thirty hours for $T$. pallidum, it is suggested, again to quote Eagle, that penicillin may be administered by any preparation and by any route which, " repeated sufficiently often and at such intervals that the effective concentration is provided for a sufficient aggregate time to kill all the organisms, and that the penicillin-free interval between injections be less than the time required for the surviving organisms to recover and to resume multiplication."

Finally, with regard to the dynamics of penicillin action in syphilis, it is interesting to speculate on the causes of penicillin failures in man as contrasted with animals. Aside from the two causes of major importance (inadequate dosage or too short duration of treatment), failure may be related to one or all of three factors. First, the organisms may be localized in tissues in which, for reasons not yet understood, penicillin is not concentrated in effective levels ; or, alternately in which (as perhaps in the nervous system) the drug is destroyed more rapidly than it can penetrate. In either of these circumstances a sterilizing level of penicillin may be attained or maintained for too short a period of time. Second, evidence begins to accumulate, as I have indicated above, that the $T$. pallidum, like other pathogenic organisms, may be divisible into strains which vary not only in their pathogenicity for man, but also in their susceptibility to treponemicidal drugs. Finally, 
there is the interesting hypothetical possibility, not as yet proved, that in certain stages of syphilis, or perhaps in individual patients with any stage of the infection, the organisms may not be undergoing active multiplication at the time of penicillin treatment. It has been clearly shown for bacterial infections other than syphilis, that penicillin is effective only against actively dividing and not against resting organisms.

\section{Other Antibiotics in the Treatment of the Venereal Diseases}

The most important new development in the United States deals with aureomycin. This new antibiotic is effective alike against a number of bacterial and rickettsial infections and against certain virus infections caused by viruses of large molecular weight. It has now been demonstrated to be effective in some degree against all the venereal diseases in which it has been tested : gonorrhœa, chancroid, lymphogranuloma venereum, granuloma inguinale, and syphilis. In gonorrhoea the drug seems unlikely to replace penicillin, which is so far uniformly effective without the appearance of penicillin-resistant strains. In chancroid, enough information as to aureomycin has not yet accumulated.

In lymphogranuloma venereum, however, this drug administered orally in doses of $250 \mathrm{mg}$. four times daily, to a total of 20 to $40 \mathrm{~g}$., seems likely to be more effective than any preparation so far tried. In granuloma inguinale, likewise, a similar dosage orally administered appears to be as effective as streptomycin, though curiously enough the organism, D. granulomatis, continues to persist in healing lesions up to the point of their final disappearance. Information is not yet available as to whether aureomycin resistance is produced, as is certainly the case with streptomycin.

In syphilis it has been shown from my own clinic that aureomycin is effective both in experimental animals and in man. It is probably much less effective, however, than penicillin; and, for the time being at any rate, its further use in syphilitic infection should be entirely on an experimental basis. It seems improbable that any preparation orally administered will be as satisfactory for the mass control of syphilis as penicillin.

The fact that aureomycin is effective in syphilis, however, is of importance with regard to its use in other venereal diseases. As with the penicillin treatment of gonorrhœa, one must guard against the possibility that persons treated with aureomycin for, for example, gonorrhœa, granuloma inguinale, etc., may have been simultaneously infected with syphilis and that this latter infection may be suppressed but not cured by aureomycin therapy.
Chloromycetin (now renamed chloroamphenicol) seems likely, on the basis of very preliminary evidence, to have the same spectrum of activity against the venereal diseases as aureomycin.

\section{REFERENCES}

Alexander, L. J., and Schoch, A. G. (in the press). "Abortive Treatment of Syphilis. Results Obtained in the Incubation, Primary, and Secondary Stages of Syphilis." Amer. J. Syph.

Boak, R. A., and Carpenter, C. M. (1949a). Ibid., 33, 8.

- (1949b). Summary of " Studies on the Isolation of $T$. pallida" presented at a Joint Symposium of the Syphilis Study Szction, National Institutes of Health, and American Venereal Disease Association, Washington, D.C., April 7, 1949.

Campbell, V. W. H., Dougherty, W. J., and Curtis, C. E. (in the press). "Delayed Administration of Oral Penicillin as Prophylaxis for Gonorrhea." Amer. J. Syph.

Cumberland, M. C., and Turner, T. B. (1949). Ibid., 33, 201.

Eagle, H. (1949). . “ The Dynamics of Penicillin Action." Presented at a Joint Symposium of the Syphilis Study Section, National Institutes of Health, and the American Venereal Disease Association, Washington, D.C., April 7, 1949.

(1948). Publ. Hlth. Rep., Wash., 63, 1411.

Farmer, T. W. (1948). J. Amer. med. Ass., 238, 480.

Goodwin, M. S., and Farber, M. S. (1948). Amer. J. Syph., 32, 409.

Hoekenga, M. T., and Farmer, T. W. (1948). Arch. intern. Med., 82, 611.

$\longrightarrow$, Buerk, M. S., and Rider, R. V. (1949). Amer. J. Syph., 33, 323.

Ingraham, N. R. Jr. (1948). Amer. J. Med., 5, 693.

Magnuson, H. J., Eägle, H., and Fleischman, R. (1948). Amer. J. Syph., 32, 1.

, and Rosenau, B. J. (1948). Ibid., 32, 418.

Nelson, R. A. Jr. (1948). Amer. J. Hyg., 48, 120.

—, Diesendruck, J. A., and Zheutlin, H. E. C. (1949). "Treponemal Immobilizing Antibodies Produced in Serum and C.S.F. During Syphilitic Infection." Presented at a Joint Symposium, Syphilis Study Section, National Institutes of Health, and American Venereal Disease Association, Washington, D.C., April 7, 1949.

$\longrightarrow$, and Mayer, M. M. (1949). J. exp. Med., 89, 369.

Newcomer, V. D., and Hannes, M. (personal communication).

Plotke, F., Eisenberg, H., Baker, A. H., and Laughlin, M. E. (in the press). "Penicillin in the Abortive Treatment of Syphilis." J. vener. Dis. Inform.

Thomas, E. W. (1948). Bull. vener. Dis. Mass. Dept. publ. Hlth, 9, 1 .

(In the press). "Experiences with Single and Multiple Treatment Schedules of Early Syphilis with Procraine Penicillin in Oil and Aluminium Monostearate. Amer. J. Syph.

Tucker, H. A. (1949). Ibid., 33, 1.

Turner, T. B., and Cumberland, M. C. (1949). "Immunological Relationships Between Strains of $T$. pallida" read before a Joint Symposium, Syphilis Study Section, National Institutes of Health, And American Venereal Disease Association, Washington, D.C., April 7, 1949. 